Open Access

\title{
Palliative transpedicular partial corpectomy without anterior vertebral reconstruction in lower thoracic and thoracolumbar junction spinal metastases
}

\author{
Chien-Chun Chang ${ }^{1}$, Yen-Jen Chen ${ }^{1,2^{*}}$, Da-Fu Lo ${ }^{1}$, Hsien-Te Chen ${ }^{1}$, Horng-Chaung Hsu ${ }^{1}$ and Ruey-Mo Lin ${ }^{3}$
}

\begin{abstract}
Background: The thoracolumbar junction is the transition from a stiff (thoracic spine) to a mobile zone (lumbar spine) and is relatively unstable compared with the thoracic and lumbar portions of the spine. The need for anterior reconstruction after a corpectomy has been emphasized by several authors. However, for patients with a relatively short life expectancy, anterior reconstruction may be unnecessary. Posterior instrumentation alone may be sufficient to provide pain relief and stability for such patients. The goal of this study was to assess the postoperative outcomes and survival rates of patients with tumor metastases of the lower thoracic spine and thoracolumbar junction (T10-L1) who underwent transpedicular partial corpectomy without anterior vertebral reconstruction.
\end{abstract}

Methods: From November 2001 to February 2015, 29 patients diagnosed with symptomatic spinal cord compression caused by tumor metastasis involving T10 to L1 underwent palliative surgery that involved a posterolateral transpedicular partial corpectomy without anterior reconstruction. The surgical indication was neurologic progression. A follow-up was conducted for all of the patients, including reviewing medical records and performing an examination in the outpatient department.

Results: The patients ranged in age from 33 to 83 years (mean, 61.6 years). Neurologic improvement by at least one Frankel grade was noted in $75.9 \%$ of the patients $(N=22)$. Neither intraoperative mortality nor implant failure was reported. The median survival rate was 7.43 months (range, $0.47-28$ months).

Conclusion: The results of this study suggest that the stability of implants can be maintained up to 28 months with satisfying functional outcome after a palliative posterolateral transpedicular partial corpectomy without anterior reconstruction.

Keywords: Anterior vertebral reconstruction, Cancer, Implant failure, Partial corpectomy, Posterior instrumentation, Posterolateral transpedicular approach, Spinal metastasis, Stability, Survival rate, Thoracolumbar junction tumor

\section{Background}

Surgery for treating spinal metastatic disease offers more benefits in walking ability and reduces the need for opioid analgesia compared with radiation therapy alone [1]. The traditional approach for treating spinal metastasis is to use posterior procedures for decompression followed

\footnotetext{
* Correspondence: yenjenc.tw@yahoo.com.tw

'Department of Orthopedic Surgery, China Medical University Hospital, No. 2, Yuh-Der Road, Taichung 404, Taiwan

${ }^{2}$ Department of Orthopedic Surgery, School of Medicine, China Medical University, Taichung, Taiwan

Full list of author information is available at the end of the article
}

by anterior column reconstruction. The need for anterior column reconstruction after tumor excision has been emphasized by many previous studies [2-4]. However, the need for anterior reconstruction has been challenged by other authors who have treated thoracic spine metastatic disease and have hypothesized that the thoracic spine has more stability than other spinal segments, making anterior reconstruction unnecessary [5]. This finding raises the question if anterior reconstruction is also unnecessary in other spine segments during treatment of carefully selected patients.

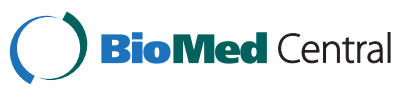


As we know, the thoracolumbar junction (TLJ) of the spine is considered the most mobile spinal segment [6], and the need for anterior reconstruction after tumor excision is theoretically more important than for other spinal segments. However, in patients with a short life expectancy, anterior reconstruction may be unnecessary and may be associated with severe morbidity and is also contraindicated in patients whose general condition is poor. Posterior instrumentation alone may provide sufficient stability and the advantage of improved pain relief.

The goals of this study were to evaluate the clinical outcomes of patients who underwent transpedicular partial corpectomy without anterior reconstruction in spinal metastases of the lower thoracic spine and TLJ (T10-L1).

\section{Methods}

This was a retrospective review of our spine-tumor database from November 2001 to February 2015 that identified 29 consecutive patients who underwent surgery for metastatic spinal diseases involving T10 to L1 by a single surgeon in our hospital. The research ethics committee of our hospital approved this retrospective analysis. All of the patients underwent a posterolateral transpedicular partial corpectomy without anterior vertebral reconstruction.

The clinical data were collected by reviewing medical records, including patient age, sex, date of operation, date of death or final follow-up, tumor histology, and preoperative and postoperative ambulatory status graded using the Frankel system. The overall survival rate was calculated from the date of surgery to the date of final follow-up or death. The survival curve was calculated using the Kaplan-Meier method.

The clinical indication for operation was symptomatic metastatic spinal cord compression with neurologic progression. A multidisciplinary team evaluated all the patients to determine their suitability to undergo surgery. Preoperative evaluation included laboratory data, plain radiography, and magnetic resonance imaging.

Posterior spinal instrumentation was performed for all the cases after adequate decompression. Local radiotherapy, targeted therapy, and systemic chemotherapy were performed according to appropriate cancer guidelines after the operation. Wound healed typically 3 to 4 weeks after the operation.

\section{Technique}

\section{Approach}

The patients were positioned prone on a Jackson spine table. A midline incision was made at least two levels above and below the tumor to expose the tumor adequately.

\section{Decompression}

Total laminectomy was performed one level above and below the affected segment. Facetectomies and pedicle resection for the affected vertebra were performed. We removed the posterior and lateral epidural tumor after ligation of the nerve roots at the affected vertebra (thoracic spine only). The tumor in the posterior vertebral body was removed after identification of the plane between the posterior longitudinal ligament and the dura in order to achieve adequate circumferential decompression. A partial corpectomy was performed and generally involved removing less than $50 \%$ of the vertebral body. The goals of the surgery were adequate decompression and palliative tumor excision, not en bloc resection.

\section{Instrumented stabilization}

Instrumentation with pedicle screws was performed two levels above and below the lesion. Anterior vertebral body reconstruction and posterolateral fusion with bone graft were not performed in any of the patients.

\section{Results}

The patients ranged in age from 33 to 83 years old (mean, $61.6 \pm 11.6$ years, 16 men, 13 women). The mean operating time was $4.6 \pm 0.93 \mathrm{~h}$. The mean intraoperative blood loss was $1181 \pm 657.6 \mathrm{ml}$. The most common metastatic tumor in our cases was lung cancer, as shown in Table 1.

Neurologic improvement was noted in 22 of 29 patients (75.9\%). Overall, $65.5 \%$ of the patients (19 of 29 ) could walk after the operation. After the operation, no patient showed deterioration of the functional scales measured by Frankel grading (Table 2). Fourteen of 24 (58.3 \%) nonambulatory (Frankel level $\mathrm{B} / \mathrm{C}$ ) patients became ambulatory (Frankel level D/E) again. For patients who survived more than 6 months, $93.3 \%$ (14 of 15) were ambulatory.

Postoperative complications are listed in Table 3. Neither intraoperative mortality nor cases requiring revision surgery were reported. Among the seven complications, only one was related to surgery. Two patients died within 30 days of the operation. One patient died because of nonsurgery-related pneumonia and sepsis. The other patient died because of respiratory failure caused by lung cancer. The median postoperative survival time was 7.43 months (range, $0.47-28$ months). The KaplanMeier curve (Fig. 1) shows that the cumulative survival rate was $52.2 \%$ at 6 months and $30.1 \%$ at 1 year. Among the patients, nine survived for more than 1 year. Three patients survived more than 2 years. Four patients were still alive at the time of this report, with follow-up times ranging from 14 to 28 months.

No implant failure was noted within the follow-up time (mean follow-up, $9.52 \pm 8.37$ months). The implants were maintained without loosening or failure up to 28 months without reconstruction (Fig. 2). 
Table 1 Demographic data of the 29 patients who underwent transpedicular partial corpectomy without anterior vertebral reconstruction for metastatic thoracolumbar diseases

\begin{tabular}{|c|c|c|c|c|c|c|}
\hline \multirow[b]{2}{*}{ Case no. } & \multirow[b]{2}{*}{ Age (years), sex } & \multirow[b]{2}{*}{ Primary tumor } & \multirow[b]{2}{*}{ aLocation } & \multirow[b]{2}{*}{ Survival days } & \multicolumn{2}{|l|}{ Frankel grade } \\
\hline & & & & & Preoperative & Postoperative \\
\hline 1 & $75, M$ & Lung & T11, L1 & 223 & $C$ & $C$ \\
\hline 2 & $69, M$ & Lung & $\mathrm{T} 12$ & 23 & $C$ & $C$ \\
\hline 3 & $59, F$ & Lung & $\mathrm{T} 11,12$ & 626 & D & $E$ \\
\hline 4 & $73, F$ & Lung & $\mathrm{T} 11,12$ & 265 & C & $E$ \\
\hline 5 & $81, \mathrm{M}$ & Lung & L1 & 115 & C & $\mathrm{D}$ \\
\hline 6 & $51, \mathrm{M}$ & Lung & $\mathrm{T} 10$ & 171 & C & C \\
\hline 7 & $33, F$ & Neuroendocrine & $\mathrm{T} 12$ & 98 & C & $\mathrm{D}$ \\
\hline 8 & $65, F$ & Lung & L1 & 422 & C & $\mathrm{E}$ \\
\hline 9 & $69, \mathrm{M}$ & Lung & $\mathrm{T} 10$ & 61 & C & $\mathrm{D}$ \\
\hline 10 & $51, F$ & Lung & T12, L1 & 803 & C & $E$ \\
\hline 11 & $76, \mathrm{M}$ & Lung & L1 & 73 & C & C \\
\hline 12 & $73, F$ & Cervical & T12, L1 & 256 & $\mathrm{D}$ & $E$ \\
\hline 13 & $51, M$ & Esophagus & L1 & 14 & C & C \\
\hline 14 & $68, M$ & Liver & L1 & 110 & B & C \\
\hline 15 & $44, F$ & Adrenal gland & $\mathrm{T} 11$ & 325 & B & $\mathrm{D}$ \\
\hline 16 & $83, F$ & Liver & $\mathrm{T} 12$ & 45 & C & C \\
\hline 17 & $67, M$ & Kidney & L1 & 43 & $C$ & C \\
\hline 18 & $55, F$ & Kidney & $\mathrm{T} 10$ & 169 & B & C \\
\hline 19 & $55, \mathrm{M}$ & Lung & $\mathrm{T} 11$ & 633 & C & $E$ \\
\hline 20 & $64, F$ & Lung & $\mathrm{T} 12, \mathrm{~L} 1$ & 299 & $\mathrm{D}$ & $E$ \\
\hline 21 & $65, F$ & Multiple myeloma & $\mathrm{T} 10$ & 450 & $C$ & $\mathrm{D}$ \\
\hline 22 & $43, F$ & Cervical & $\mathrm{T} 11$ & 73 & $\mathrm{D}$ & $\mathrm{E}$ \\
\hline 23 & $49, M$ & Pancreas & L1 & b851 & C & $\mathrm{E}$ \\
\hline 24 & $59, \mathrm{M}$ & Lung & $\mathrm{T} 12, \mathrm{~L} 1$ & ${ }^{b} 829$ & C & E \\
\hline 25 & $55, \mathrm{M}$ & Lung & $\mathrm{T} 11$ & 104 & C & C \\
\hline 26 & $49, M$ & Rectus & $\mathrm{T} 11,12$ & 185 & C & $E$ \\
\hline 27 & $58, \mathrm{M}$ & Lung & $\mathrm{T} 11$ & 103 & C & $\mathrm{D}$ \\
\hline 28 & $70, M$ & Prostate & $\mathrm{T} 12$ & ${ }^{b} 484$ & D & E \\
\hline 29 & $62, F$ & Multiple myeloma & $\mathrm{T} 11$ & ${ }^{b} 432$ & C & $\mathrm{D}$ \\
\hline
\end{tabular}

a"Location" means the segment where we performed the operation

${ }^{\mathrm{b}}$ Cases of numbers $23,24,28$, and 29 were still alive at the time of most recent contact

Table 2 Functional status: preoperative versus postoperative Frankel grading

\begin{tabular}{|c|c|c|c|c|c|}
\hline \multirow{2}{*}{$\begin{array}{l}\text { Preoperative } \\
\text { grading }\end{array}$} & \multicolumn{5}{|c|}{ Postoperative grading } \\
\hline & $\bar{A}$ & $B$ & $C$ & $\mathrm{D}$ & $E$ \\
\hline \multicolumn{6}{|l|}{$\bar{A}$} \\
\hline B & & & 3 & 1 & \\
\hline C & & & 7 & 6 & 7 \\
\hline $\mathrm{D}$ & & & & & 5 \\
\hline$E$ & & & & & \\
\hline
\end{tabular}

\section{Discussion}

The posterolateral transpedicular approach (PTA) with circumferential decompression and reconstruction has become widely accepted in treating spinal metastasis, especially in cases with circumferential tumor compression or multilevel spinal involvement. Adequate decompression and stabilization are the goals of this surgery. The need for anterior reconstruction for adequate stabilization in the PTA has been emphasized by several authors [2-4]. Two biomechanical studies have demonstrated that circumferential spinal fixation provides superior construct stability compared with anterior or posterior fixation alone $[7,8]$. 
Table 3 Postoperative complication

\begin{tabular}{ll}
\hline Complication & No. of patients \\
\hline Neurologic progression & 0 \\
CSF leakage & 1 \\
Wound dehiscence/infection & 0 \\
Intraoperative mortality & 0 \\
Respiratory failure & 1 \\
Gl bleeding/gastrointestinal perforation & 2 \\
Pulmonary embolism & 0 \\
Revision surgery & 0 \\
Local recurrence & 1 \\
30-day mortality & 2 \\
\hline
\end{tabular}

Anterior reconstruction is not completely without risk. Akeyson et al. studied 25 patients who underwent a single-stage complete spondylectomy, vertebral body reconstruction, and posterior segmental spinal stabilization for malignant metastatic disease of the thoracolumbar spine [9]. The overall complication rate was $48 \%$, and the most severe complications were related to migration of the material used for reconstruction. Anterior reconstruction during PTA with polymethylmethacrylate replacement may have a $16 \%$ dislodgement rate and may require revision surgery [9]. Reconstruction with the Steinmann

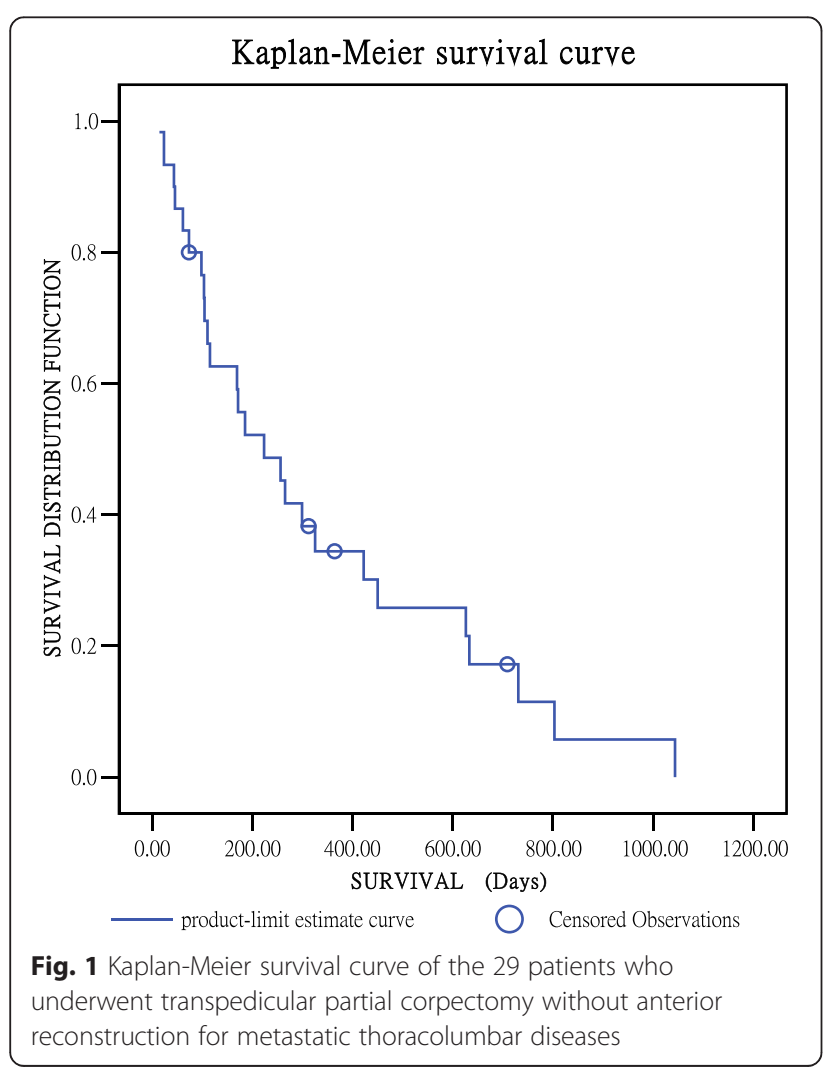

pin and cement also showed a complication rate of approximately $14.3 \%$ [10]. Even when a modern expandable cage was used, complications were as high as 10-21\% [11-14]. Anterior vertebral reconstruction during PTA also increases blood loss and operation time and may increase morbidity and complications. These factors raise considerable concerns for patients with metastatic tumors and poor general condition because they may result in delayed treatment with chemotherapy/target therapy or radiotherapy.

T10-L1 is a transition from the stiff (thoracic spine) to the mobile zone (lumbar spine) and is relatively unstable compared with the thoracic and lumbar spine. The TLJ is a frequent site of spinal trauma, and up to $67 \%$ of operative cases involve TLJ traumatic injuries [6]. Previous biomechanical studies have demonstrated that anterior column integrity determines the risk of sagittal collapse and kyphosis at the thoracolumbar spine [15]. Oda et al. studied the stability of five reconstruction methods after total spondylectomy in cadaveric spines and concluded that short circumferential instrumentation provided more stability than did multilevel posterior instrumentation alone [16]. According to these studies, anterior column reconstruction is crucial in treating lower thoracic and TLJ spinal fractures, and, basically, treating metastatic spinal tumors involving T10-L1 should also follow this rule. However, the complications of anterior reconstruction are an important concern in treating spinal metastases.

Previous studies have reported the results of the PTA without anterior reconstruction, but no study had directly focused on tumors involving T10-L1. Bridwell et al. [17] studied 25 patients with metastatic spine disease treated with PTA and posterior segmental spinal instrumentation and reported no cases of implant failure; however, only seven cases involved T10 to L1. Walter et al. studied 57 consecutive patients with metastatic vertebral tumors who were treated using PTA without anterior reconstruction [18]. The complication rate was only $5.3 \%$, including one seroma and two superficial wound infections. No implant failure was reported. However, the study by Walter et al. involved only ten cases at T10-L1. Cho et al. [19] studied 21 consecutive patients with metastatic tumors who were treated using PTA without anterior reconstruction and reported a complication rate of $19 \%$ (4 of 21). However, Cho's study involved only 13 cases at T10-L1. Based on our research, no previous studies have directly focused on metastatic tumors involving T10 to L1 treated using PTA without anterior reconstruction.

In this study, no cases of implant loosening or failure were noted by follow-up radiography (mean follow-up, $9.52 \pm 8.37$ months), and three patients survived more than 2 years without implant failure or loosening. 

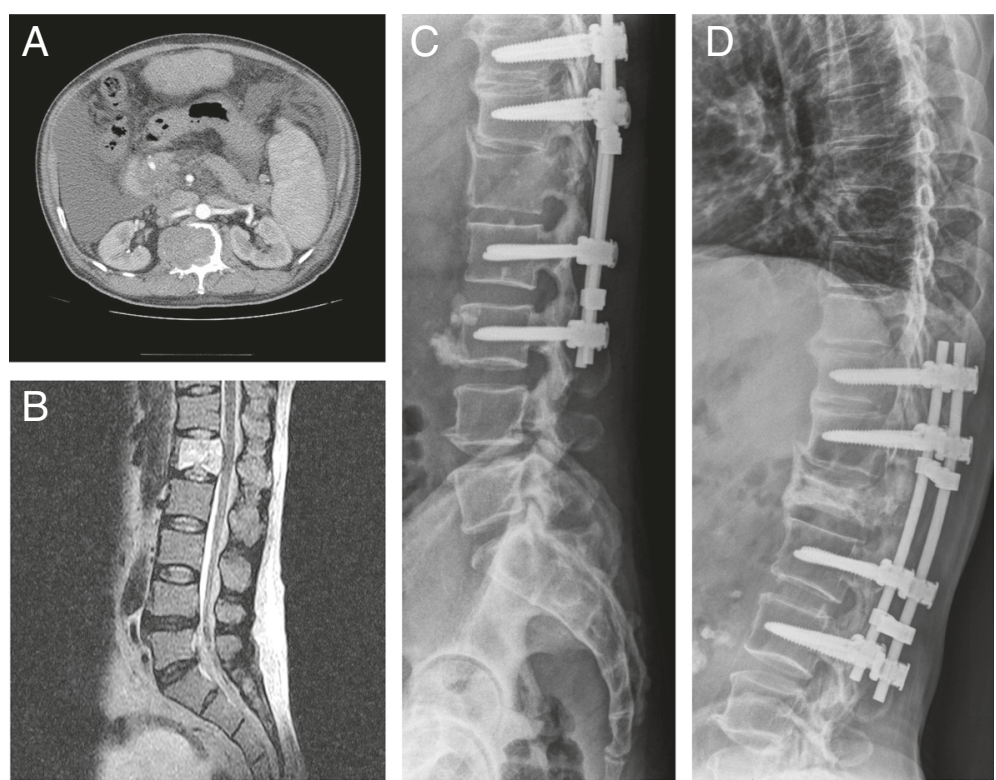

Fig. 2 Preoperative and postoperative images of a 49-year-old man with L1 vertebral metastatic spinal cord compression from pancreatic cancer who underwent surgery using the posterolateral transpedicular approach without anterior vertebral reconstruction. The CT angiography (a) and MRI image (b) demonstrate metastatic spinal tumor with cord compression at L1. The immediate postoperative radiographs (c) and the 28-month follow-up radiographs (d) demonstrate no screw loosening or implant failure

The greatest concerns about using PTA without anterior reconstruction are the durability and stability of posterior instrumentation. We attempted to resolve this problem using two methods. First, no more than $50 \%$ of the vertebral body was resected. Bilsky et al. [20] suggested that vertebral body reconstruction of the spine may be unnecessary if less than $50 \%$ of the vertebral body has been resected. These methods can achieve adequate decompression without sacrificing stability. Second, all of the patients in this study underwent instrumentation two levels above and below the tumor lesion after the PTA. Some biomechanical studies have demonstrated that multilevel fixation (long constructs) have proved to be more reliable and effective in treating thoracolumbar injuries-with or without anterior reconstruction-compared with shortsegment fixation $[14,15]$. If the patient's life expectancy is longer than 2 years, or when stability is a concern, further anterior reconstruction may be attempted later.

The goals of the palliative operation in treating metastatic spine tumor are to decompress the tumor for functional improvement and to stabilize the spine structure for pain relief rather than en bloc resection of the tumor. With fewer postoperative complications, patients can accept further oncologic therapies (including radiotherapy, chemotherapy, and targeted therapy) more quickly and may have better functional status and quality of life. Because of the complications associated with anterior reconstruction, posterior instrumentation alone seems to be more suitable for selected patients. These patients can recover more quickly and smoothly when this less invasive method is used. Earlier systemic oncologic therapies and radiotherapy may lower the recurrence rate of the metastatic spinal tumor. With this method, only one local recurrence of previous metastatic spinal tumor was noted in our series.

There are still some limitations of this study. First, this was a retrospective study. Second, the sample size is relatively small because we focused on the level of T10 to L1. Third, this study did not have a control group. Although the article lacks a control group to compare against, we believe that the rate of neurological improvement using these methods is not inferior to addition of anterior column reconstruction. The neurological improvement rate of corpectomy with anterior reconstruction ranges from 29.6 to $61.5 \%$ [10, 12, 13]. In our study, neurological improvement was noted in 22 of 29 patients (75.9 \%). According to these studies, we believe that PTA without anterior reconstruction provides a comparable rate of neurological improvement and less complication compared with circumferential decompression and anterior reconstruction. With the principles mentioned above, patients with symptomatic tumor metastasis involving T10 to L1 can be treated simply with palliative PTA and posterior instrumentation without anterior reconstruction with satisfying functional results.

\section{Conclusions}

The PTA without anterior reconstruction is an option for treating T10-L1 metastases. The results of this study revealed that applying these principles and methods can 
maintain implant stability for up to 28 months without anterior vertebral reconstruction in patients with T10-L1 metastases.

\section{Abbreviations}

PTA: posterolateral transpedicular approach; TLJ: thoracolumbar junction.

\section{Competing interests}

The authors declare that they have no competing interests.

\section{Authors' contributions}

CCC helped to search the literature and to draft the manuscript. YJC carried out the interpretation of data and statistical analysis, provided critical revision of the manuscript for intellectual content, and performed the final checking of this manuscript. DFL and HTC participated in the conception, design, and coordination. RML and $\mathrm{HCH}$ supervised the whole study. All authors read and approved the final manuscript.

\section{Authors' information}

CCC, YJC, DFL, HTC, HCH, and RML have an MD degree. CCC, YJC, DFL, $\mathrm{HTC}$, and $\mathrm{HCH}$ are all from the Department of Orthopedics, China Medical University Hospital, China Medical University, Taichung, Taiwan. RML is from the Department of Orthopedic Surgery, Tainan Municipal An-Nan Hospital, Tainan, Taiwan.

\section{Acknowledgements}

There is no funding related to this paper for all the authors. The authors would like to acknowledge Dr. Wai-Man Cheang for her help in the data acquisition.

\section{Author details}

${ }^{1}$ Department of Orthopedic Surgery, China Medical University Hospital, No. 2, Yuh-Der Road, Taichung 404, Taiwan. '2Department of Orthopedic Surgery, School of Medicine, China Medical University, Taichung, Taiwan.

${ }^{3}$ Department of Orthopedic Surgery, Tainan Municipal An-Nan Hospital, Tainan, Taiwan.

Received: 7 April 2015 Accepted: 2 July 2015

Published online: 17 July 2015

\section{References}

1. Patchell RA, Tibbs PA, Regine WF, Payne R, Saris S, Kryscio RJ, et al. Direct decompressive surgical resection in the treatment of spinal cord compression caused by metastatic cancer: a randomised trial. Lancet. 2005;366:643-8.

2. Harrington $\mathrm{KD}$. The use of methylmethacrylate for vertebral-body replacement and anterior stabilization of pathological fracture-dislocations of the spine due to metastatic malignant disease. J Bone Joint Surg Am. 1981:63:36-46.

3. McAfee PC, Bohlman HH, Ducker T, Eismont FJ. Failure of stabilization of the spine with methylmethacrylate. A retrospective analysis of twenty-four cases. J Bone Joint Surg Am. 1986;68:1145-57.

4. Siegal T, Tiqva P, Siegal T. Vertebral body resection for epidural compression by malignant tumors. Results of forty-seven consecutive operative procedures. J Bone Joint Surg Am. 1985;67:375-82.

5. Chen YJ, Hsu HC, Chen KH, Li TC, Lee TS. Transpedicular partial corpectomy without anterior vertebral reconstruction in thoracic spine metastasis. Spine (Phila Pa 1976). 2007:32:E623-6.

6. Reinhold M, Knop C, Beisse R, Audigé L, Kandziora F, Pizanis A, et al. Operative treatment of 733 patients with acute thoracolumbar spinal injuries: comprehensive results from the second, prospective, Internet-based multicenter study of the Spine Study Group of the German Association of Trauma Surgery. Eur Spine J. 2010;19:1657-76.

7. Chen HH, Wang WK, Li KC, Chen TH. Biomechanical effects of the body augmenter for reconstruction of the vertebral body. Spine (Phila Pa 1976). 2004;29:E382-7.

8. Wang $X Y$, Dai $L Y, X u H Z$, Chi YL. Biomechanical effect of the extent of vertebral body fracture on the thoracolumbar spine with pedicle screw fixation: an in vitro study. J Clin Neurosci. 2008:15:286-90.

9. Akeyson EW, McCutcheon IE. Single-stage posterior vertebrectomy and replacement combined with posterior instrumentation for spinal metastasis. J Neurosurg. 1996;85:211-20.
10. Wang JC, Boland P, Mitra N, Yamada Y, Lis E, Stubblefield M, et al. Single-stage posterolateral transpedicular approach for resection of epidural metastatic spine tumors involving the vertebral body with circumferential reconstruction: results in 140 patients. Invited submission from the Joint Section Meeting on Disorders of the Spine and Peripheral Nerves, March 2004. J Neurosurg Spine. 2004;1:287-98.

11. Eleraky M, Papanastassiou I, Tran ND, Dakwar E, Vrionis FD. Comparison of polymethylmethacrylate versus expandable cage in anterior vertebral column reconstruction after posterior extracavitary corpectomy in lumbar and thoraco-lumbar metastatic spine tumors. Eur Spine J. 2011;20:1363-70.

12. Shen FH, Marks I, Shaffrey C, Ouellet J, Arlet V. The use of an expandable cage for corpectomy reconstruction of vertebral body tumors through a posterior extracavitary approach: a multicenter consecutive case series of prospectively followed patients. Spine J. 2008;8:329-39.

13. Viswanathan A, Abd-El-Barr MM, Doppenberg E, Suki D, Gokaslan Z, Mendel $E$, et al. Initial experience with the use of an expandable titanium cage as a vertebral body replacement in patients with tumors of the spinal column: a report of 95 patients. Eur Spine J. 2012;21:84-92.

14. Metcalfe S, Gbejuade H, Patel NR. The posterior transpedicular approach for circumferential decompression and instrumented stabilization with titanium cage vertebrectomy reconstruction for spinal tumors: consecutive case series of 50 patients. Spine (Phila Pa 1976). 2012;37:1375-83.

15. McLain RF. The biomechanics of long versus short fixation for thoracolumbar spine fractures. Spine (Phila Pa 1976). 2006;31:S70-9.

16. Oda I, Cunningham BW, Abumi K, Kaneda K, McAfee PC. The stability of reconstruction methods after thoracolumbar total spondylectomy. An in vitro investigation. Spine (Phila Pa 1976). 1999;24:1634-8.

17. Bridwell KH, Jenny AB, Rich KM ST, Brubb RL. Posterior segmental spinal instrumentation (PSSI) with posterolateral decompression and debulking for metastatic thoracic and lumbar spine disease. Limitations of the technique. Spine (Phila Pa 1976). 1988;13:1383-94.

18. Walter J, Reichart R, Waschke A, Kalff R, Ewald C. Palliative considerations in the surgical treatment of spinal metastases: evaluation of posterolateral decompression combined with posterior instrumentation. J Cancer Res Clin Oncol. 2012;138:301-10.

19. Cho DC, Sung JK. Palliative surgery for metastatic thoracic and lumbar tumors using posterolateral transpedicular approach with posterior instrumentation. Surg Neurol. 2009;71:424-33.

20. Bilsky MH, Boland P, Lis E, Raizer JJ, Healey JH. Single-stage posterolateral transpedicle approach for spondylectomy, epidural decompression, and circumferential fusion of spinal metastases. Spine (Phila Pa 1976). $2000 ; 25: 2240-9$

\section{Submit your next manuscript to BioMed Central and take full advantage of:}

- Convenient online submission

- Thorough peer review

- No space constraints or color figure charges

- Immediate publication on acceptance

- Inclusion in PubMed, CAS, Scopus and Google Scholar

- Research which is freely available for redistribution 